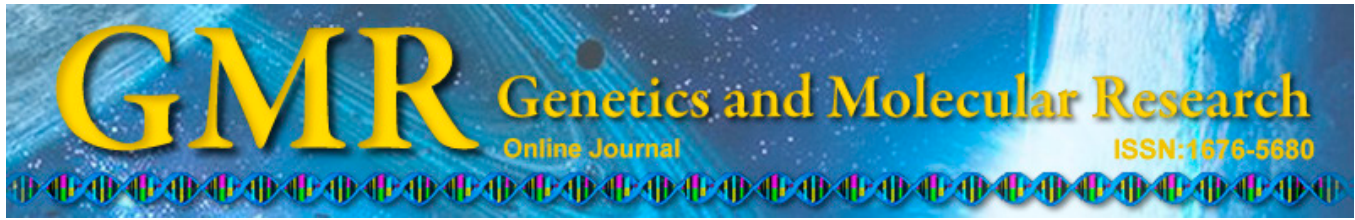

\title{
Identification, molecular characterization, and tissue expression of parathyroid hormone-related protein gene (PTHrP) from water buffalo (Bubalus bubalis)
}

J. Liu ${ }^{1 *}$, L.D. Qian ${ }^{2 *}$, J.L. Huo ${ }^{1 *}$, B.L. Bi ${ }^{1}$, D.L. Li ${ }^{3,4}$, S.F. Wang ${ }^{1}$, T. Chen ${ }^{5}$, L.J. Li ${ }^{1}$, H.M. Mao ${ }^{1}$ and Y.W. Miao ${ }^{1}$

${ }^{1}$ Faculty of Animal Science and Technology, Yunnan Agricultural University, Kunming, Yunnan, China ${ }^{2}$ Department of Husbandry and Veterinary, Yunnan Vocational and Technical College of Agriculture, Kunming, Yunnan, China ${ }^{3}$ Domestic Animal Breeding and Crossbreed-Improvement Station of Yunnan Province, Kunming, China ${ }^{4}$ Yunnan Institute of BAFULE Buffalo Science and Technology, Kunming, Yunnan, China

${ }^{5}$ Animal Husbandry and Veterinary Station of Mangshi City,

Mangshi, Yunnan, China

*These authors contributed equally to this study. Corresponding author: Y.W. Miao E-mail: yongwangmiao999@163.com / miaoyw1@ynau.edu.cn

Genet. Mol. Res. 14 (1): 2290-2301 (2015)

Received April 4, 2013

Accepted October 20, 2014

Published March 27, 2015

DOI http://dx.doi.org/10.4238/2015.March.27.14

ABSTRACT. Parathyroid hormone-related protein (PTHrP) is involved in the deposition of milk calcium in mammal lactation, but its role in buffalo is unclear. In this study, the full-length coding sequence of the water buffalo $\mathrm{PTHr} P$ gene was first isolated using reverse transcriptionpolymerase chain reaction. The protein was then subjected to molecular 
characterization using bioinformatic methods, and the tissue expression pattern was further assayed by semi-quantitative reverse-transcription polymerase chain reaction. The water buffalo $P T H r P$ gene contains an open reading frame of 534 base pairs encoding a polypeptide of 177 amino acid residues, a theoretical molecular weight of $20.32 \mathrm{kDa}$, and an isoelectric point of 10.00. In addition, water buffalo PTHrP was predicted to contain a signal peptide, a typical hydrophobic region with no hydrophobic transmembrane regions, and to exert its function in the cell nucleus. A conserved domain of parathyroid superfamily from amino acids 34-114 was observed in the polypeptide. Sequence comparison and the phylogenetic analysis showed that the sequence of the water buffalo PTHrP protein shared high homology with that of other mammals, particularly cattle and goat. Among the 16 tissues examined, the PTHrP gene was only expressed in adipose tissue, placenta, uterine wall, hypophysis, and mammary gland tissue, but gene expression levels were higher in the uterus wall and adipose tissue. The results of this study suggest that the $P T H r P$ gene plays an important role in the deposition of milk calcium of water buffalo.

Key words: Bioinformatic analysis; cDNA cloning; Water buffalo; Parathyroid hormone-related protein; Tissue expression analysis

\section{INTRODUCTION}

Parathyroid hormone-related protein (PTHrP) was first identified in animal tumors and associated with malignant humoral hypercalcemia in 1987 (Moseley et al., 1987; Hoey et al., 2003). PTHrP is structurally related to parathyroid hormone (PTH) (Schlüter, 1999). PTHrP has a similar structure to the $\mathrm{NH}_{2}$-terminal region of PTH. Additionally, $\mathrm{PTH}$ and PTHrP exert identical effects on classical target cells in the bone and kidney. However, PTHrP and PTH differ in 3 important aspects: 1) PTHrP is synthesized and released by diverse tissues rather than by the parathyroid gland; 2) the $\mathrm{COOH}$-terminus of PTHrP is longer than that of $\mathrm{PTH}$; 3) PTH plays a role as an endocrine regulator of calcium homeostasis, while PTHrP is a paracrine or autocrine factor rather a classical hormone (Schlüter, 1999).

Recently, PTHrP was found to have pivotal functions in regulating cell differentiation, cell proliferation, and organogenesis (Escande et al., 2001; Amizuka et al., 2002). Previous studies examining tumor pathophysiology showed that PTHrP plays roles in the development, homeostasis, and pathophysiology of injury and cancer (Bouvet et al., 2002; Deftos, 2002; Hastings, 2004). Some studies revealed that PTHrP is related to calcium (Ca) deposition and its functions in the development of the hair follicles, breast, teat, bone, and teeth (Karaplis et al., 1994; Lanske et al., 1996; Lam et al., 2000; Escande et al., 2001). Mice with knockout of the PTHrP gene were characterized by chondrodysplasia (Amizuka et al., 2002; Stewart, 2002). A study in mice suggested that during lactation, mammary epithelial cells are a source of circulating PTHrP, which participates in the mobilization of skeletal calcium for milk production (VanHouten et al., 2003; Boras-Granic and Wysolmerski, 2012). A study of Holstein dairy cows showed that mammary PTHrP is closely related to Ca concentration in milk (Onda et al., 2006a). 
In humans, the $P T H r P$ gene consists of 9 exons and 8 introns, with a coding sequence (CDS) of 534 base pairs (bp) (Martin et al., 1989; Clemens et al., 2001). Both cattle and goat PTHrP genes contain 5 exons with CDSs of 534 bp (Wojcik et al., 1998; Yang et al., 2010). The PTHrP gene is widely expressed in fetal and adult tissues, such as the mammary gland, lung, heart, liver, small intestines, skeletal muscle, and kidney (Wysolmerski et al., 1995; Schlüter, 1999; Lam et al., 2000; Amizuka et al., 2002; Li et al., 2011).

PTHrP plays an important role in Ca deposition and milk Ca content in mammals. Milk $\mathrm{Ca}$ is one of the most important components in the milk and is related to the sensual and technological qualities of dairy products. Therefore, the $P T H r P$ gene is a key candidate gene for normal breast development and milk traits. The PTHrP gene has been studied in human, mouse, cattle, and goat, but there have been no reports in dairy buffalo. In the present study, we cloned the full-length CDS of the water buffalo PTHrP gene using an in silico method and used a basic bioinformatic approach to predict the physicochemical properties of this protein. We examined the gene tissue expression levels in various tissues using semi-quantitative reverse-transcription polymerase chain reaction (RT-PCR).

\section{MATERIAL AND METHODS}

\section{Sample collection}

All procedures for sample collection were performed in accordance with the Guide for Animal Care and Use of Experimental Animals and approved by the Institutional Animal Care and Use Committee of Yunnan Agricultural University. Sixteen fresh tissues were collected from 10 perinatal Binglangjiang buffalo in Yunnan Province, China, including the heart, duodenum, spleen, liver, pancreas, placenta, mammary gland, skin, lung, brain, kidney, adipose tissue, ovary, uterine wall, longissimus dorsi, and hypophysis tissues. These samples were collected immediately after slaughtering, frozen in liquid nitrogen, and stored at $-80^{\circ} \mathrm{C}$. All individuals sampled were in the lactation stage and had no direct blood relationships.

\section{Total RNA extraction and cDNA synthesis}

The total RNA was isolated using the RNAiso Plus (TaKaRa, Shiga, Japan) in accordance with manufacturer instructions. Genomic DNA was removed with RNase-free DNase I (TaKaRa). The concentration and purity of total RNA were assayed using a spectrophotometer. First-strand cDNA was synthesized from $3 \mu \mathrm{g}$ total RNA using an oligo (dT) ${ }_{18}$ primer and the M-MLV reverse transcriptase (Invitrogen, Carlsbad, CA, USA). The efficiency of reverse transcription was assessed by $2 \%$ agarose gel electrophoresis.

\section{Isolation of water buffalo PTHrP gene}

To isolate the water buffalo PTHrP gene, we designed a set of primers based on the sequences of the cattle PTHrP gene (NM_174753) and its highly homologous expressed sequence tags (ESTs) using the oligo 6 software. The primers were as follows: 5'-CGGTTATTATTTCGGAGGAG-3' (forward) and 5'-GGGGAGACAGTTTTATTCCA-3' (reverse). RT-PCR was performed using the pooled cDNAs from different buffalo tissues as the template. The PCR system of this study was $25 \mu \mathrm{L}$ reaction mixture, containing $2.5 \mu \mathrm{L}$ 
cDNA (50 ng/ $\mu \mathrm{L}), 2.0 \mu \mathrm{L}$ dNTPs (2.5 mM, TaKaRa), $2.5 \mu \mathrm{L}$ 10x Taq DNA polymerase buffer ( $\mathrm{Mg}^{2+}$ Plus), $0.5 \mu \mathrm{L} 10 \mu \mathrm{M}$ forward primer, $0.5 \mu \mathrm{L} 10 \mu \mathrm{M}$ reverse primer, $0.25 \mu \mathrm{L}$ Ex Taq DNA polymerase $(5 \mathrm{U} / \mu \mathrm{L}, \mathrm{TaKaRa})$, and $16.75 \mu \mathrm{L}$ sterile water. The amplification conditions were as follows: initial denaturation at $95^{\circ} \mathrm{C}$ for $5 \mathrm{~min}$, followed by 35 cycles at $94^{\circ} \mathrm{C}$ for 30 $\mathrm{s}, 54^{\circ} \mathrm{C}$ for $45 \mathrm{~s}$, and $72^{\circ} \mathrm{C}$ for $1.5 \mathrm{~min}$, then a 10 -min extension at $72^{\circ} \mathrm{C}$; finally, the reaction was held at $4^{\circ} \mathrm{C}$.

\section{Bioinformatic analyses}

Nucleotide sequence similarity of the PTHrP gene was carried out on the NCBI server using BLAST program (http://www.ncbi.nlm.nih.gov/BLAST). Protein domains were analyzed using the Conserved Domain Architecture Retrieval Tool of BLAST at the NCBI Server (http://www.ncbi.nlm.nih.gov/BLAST). A program on the ExPASy server (http://au.expasy. org/) was used to calculate the theoretical molecular weight and isoelectric point of the PTHrP protein. The signal peptide was predicted using the SignalP4.0 server (http://www.cbs.dtu.dk/ services/SignalP/). Subcellular localization was determined by PSort II (http://psort.hgc.jp/). Transmembrane topology in protein was predicted by TMHMM-2.0 Server (http://www.cbs. dtu.dk/services/TMHMM-2.0/). PTHrP protein hydrophobicity was analyzed using a program on the ExPASy server (http://web.expasy.org/cgi-bin/protscale/protscale.pl). Nucleotide sequences and deduced amino acid sequences were aligned using ClusterX, and a phylogenetic tree was constructed using the MEGA 4.0 software based on the Kimura 2-parameter model with the neighbor-joining method. The secondary structure and 3-dimensional (3-D) structure of the deduced amino acid sequence was predicted using SOPMA (http://npsa-prabi.ibcp.fr/ cgi-bin/npsa_automat.pl?page=npsa_sopma.html) and SPDBV 4.04 (http://www.expasy.org/ swissmod/SW'ISSM ODEL.html), respectively.

\section{Tissue differential expression analysis of water buffalo PTHrP}

Semi-quantitative RT-PCR was carried out to determine PTHrP gene expression levels in 16 water buffalo tissues. The primers, reaction system, and protocol used for semiquantitative RT-PCR were the same as those described above. In this study, the $18 s r R N A$ gene was selected as an internal control because of its constant expression level in diverse tissues. The primers used for $18 s r R N A$ gene were as follows: 5'-GGACGTCTAAGGGCATCAG-3' (forward) and 5'-AATTCCGATAACGAAGAGACT-3' (reverse). The PCR system and reaction conditions for $18 s \mathrm{~s} R N A$ were similar to those described for the $P T H r P$ gene, except for the annealing temperature at $55^{\circ} \mathrm{C}$ and extension time for $1 \mathrm{~min}$.

\section{RESULTS}

\section{Isolation and sequencing of the PTHrP gene}

The length of the RT-PCR product in this study was 798 bp (Figure 1). The sequence obtained in this study showed high homology with the PTHrP genes of humans, mouse, cattle, and goat, but was not homologous to any of the known water buffalo genes. The full-length CDS of buffalo PTHrP gene was $534 \mathrm{bp}$, encoding a polypeptide composed of 177 amino acid residues (Figure 2). The CDS sequence was deposited in the NCBI database under accession 


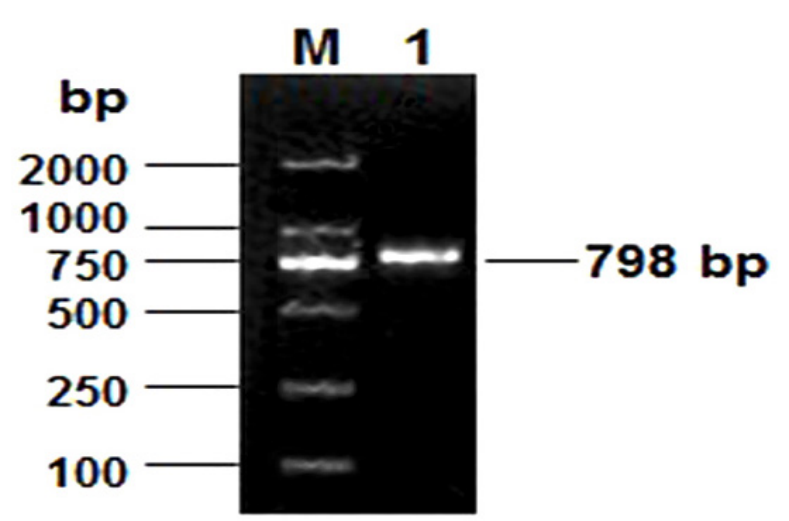

Figure 1. Reverse-transcription polymerase chain reaction (RT-PCR) image for water buffalo PTHrP gene. Lane $M=$ DL2000 DNA marker; lane 1 = PCR product.

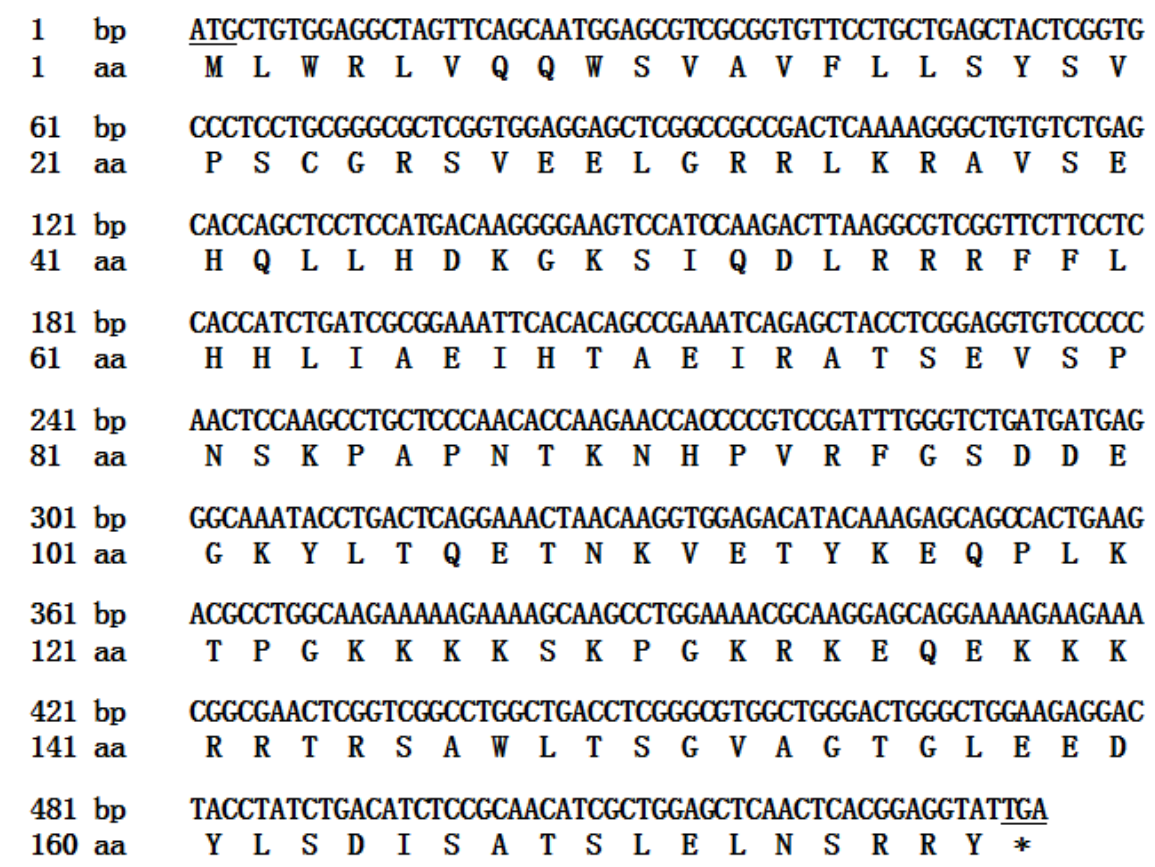

Figure 2. Complete coding sequence (CDS) of water buffalo $P T H r P$ gene and its deduced amino acids. ATG $=$ start codon; TGA $=$ stop codon denoted with an asterisk.

No. JX962778.

Physical and chemical characteristics of the PTHrP protein

The theoretical isoelectric point and molecular weight of the water buffalo PTHrP protein were 10.00 and $20.32 \mathrm{kDa}$, respectively. Signal peptide prediction revealed that water buffalo PTHrP included an N-terminal signal peptide sequence (aa 1-24; Figure 3). Analysis of cytoplas- 
mic/nuclear localization suggested that the PTHrP might play key roles in the cell nucleus with high reliability (94.1\%). Transmembrane region prediction suggested that water buffalo PTHrP was not a potential membrane protein. Hydropathy analysis showed that the protein contained 1 typical hydrophobic region (Figure 4). Conserved domain prediction showed that water buffalo PTHrP contained a conserved domain of the parathyroid superfamily (aa 34-114) (Figure 5).

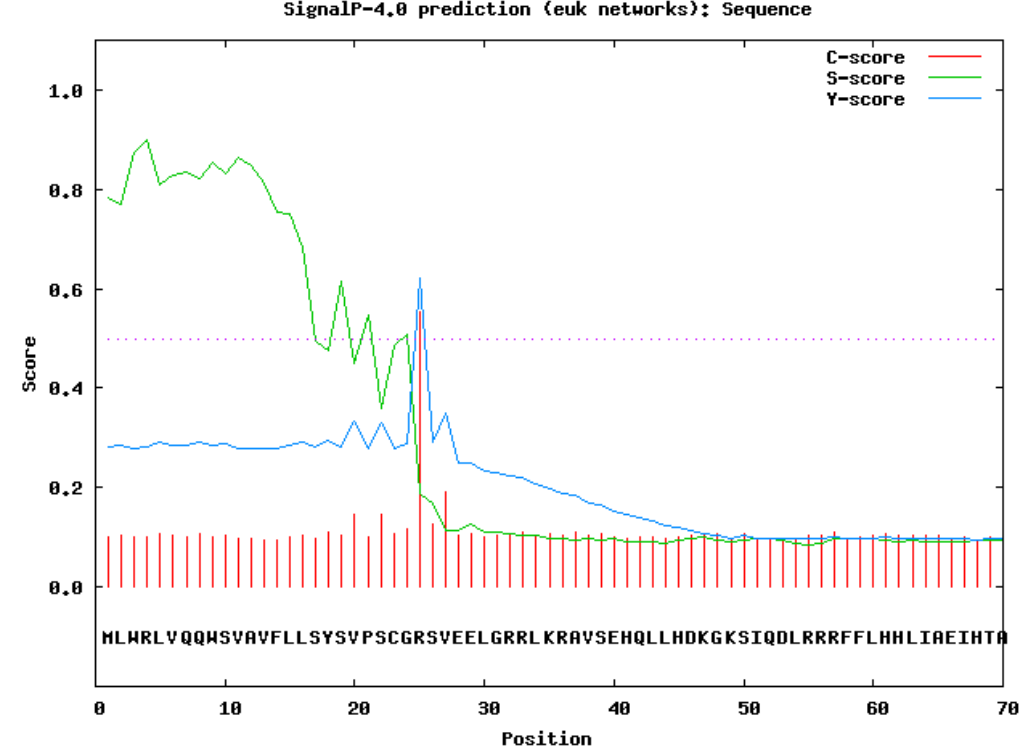

Figure 3. Signal peptide prediction of water buffalo PTHrP protein.

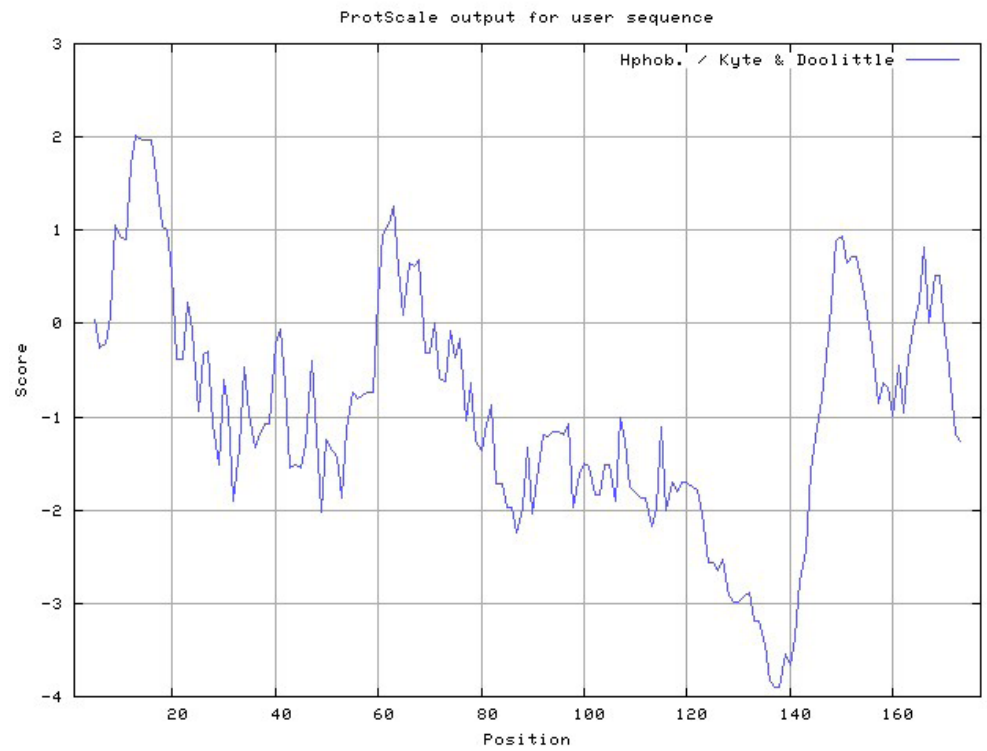

Figure 4. Hydrophobicity structure prediction of water buffalo PTHrP by ProtScale. Score $>0$ means hydrophobic; score $<0$ means hydrophilic. 


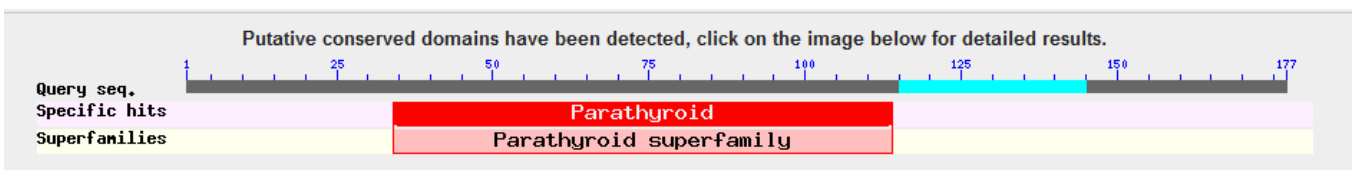

Figure 5. Putative conserved domain of water buffalo PTHrP protein.

In this study, 5 types of modified sites were detected in some amino acid residues of the water buffalo PTHrP protein, including 6 casein kinase II phosphorylation sites (26SveE-29, 50-SiqD-53, 97-SddE-100, 113-TykE-116, 155-tGLE-158, 168-TslE-171), 3 amidation sites (30-lGRR-33, 122-PgKK-125, 130-Pgkr-133), 3 protein kinase C phosphorylation sites (108-TnK-110, 113-TyK-115, 174-SrR-176), 2 cAMP- and cGMP-dependent protein kinase phosphorylation sites (25-KKkS-128, 140-KRrT-143), and $1 \mathrm{~N}$-myristoylation site (151-GVagTG-156).

\section{Polymorphisms, sequence identity, and phylogenetic tree construction}

No polymorphisms were found in the CDS of the PTHrP gene in the 10 water buffalo. The amino acid sequence of water buffalo PTHrP showed high homology with 10 species: 98.3\% with Bos taurus (NP_777178), 97.7\% with Capra hircus (ADK36630), 92.7\% with Canis lupus familiaris (NP_001003303), 89.8\% with Equus caballus (NP_001157453), 91.5\% with Halichoerus grypus (CAH39861), 90.4\% with Homo sapiens (NP_945316), 85.3\% with Mus musculus (NP_032996), 89.3\% with Papio anubis (XP_003906208), 86.4\% with Rattus norvegicus (NP_036768), and 92.1\% with Sus scrofa (NP_999081). Alignments of PTHrP amino acid sequences among 11 species are presented in Figure 6. The signal peptide is presented in the green box and the conserved domain is in the red box. The sequence comparison revealed 4 amino acid differences in PTHrP protein between water buffalo and other Bovidae species. The amino acid sequences of the parathyroid superfamily domain of the PTHrP were highly homologous and conserved among different species, but the sequences in $\mathrm{N}$-terminus and particularly the $\mathrm{C}$-terminus varied among different species.

Evolutionary relationships depended upon the PTHrP sequences and are presented in Figure 7. Phylogenetic analysis showed that water buffalo PTHrP clustered together with cattle and goat.

\section{Structural analysis of PTHrP protein}

Secondary structure analysis showed that water buffalo PTHrP consisted of 65 aa $(36.72 \%)$ alpha helices, 19 aa (10.73\%) extended strands, 5 aa (2.82\%) beta turns, and 88 aa $(49.72 \%)$ random coils (Figure 8), suggesting that a significant number of the amino acids in the PTHrP protein are likely to form alpha helices and random coils. The 3-D structure of the PTHrP protein was predicted based on the homology modeling method (Figure 9). The 3-D 


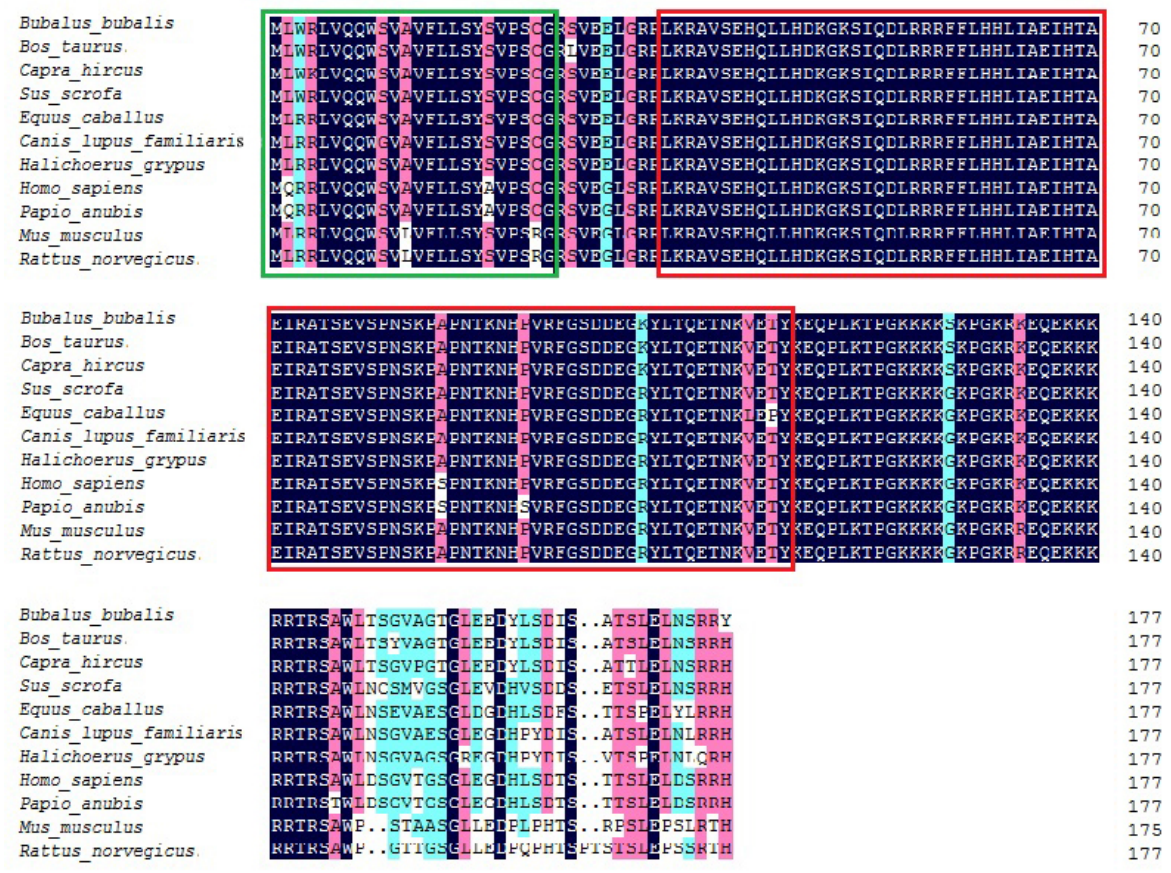

Figure 6. Alignment of the amino acid sequences encoded by the Bubalus bubalis PTHrP gene and other 10 amino acid sequences by PTHrP gene from Bos taurus (NP_777178), Canis lupus familiaris (NP_001003303), Capra hircus (ADK36630), Equus caballus (NP_001157453), Halichoerus grypus (CAH39861), Homo sapiens (NP_945316), Mus musculus (NP_032996), Papio anubis (XP_003906208), Rattus norvegicus (NP_036768), and Sus scrofa (NP_999081).

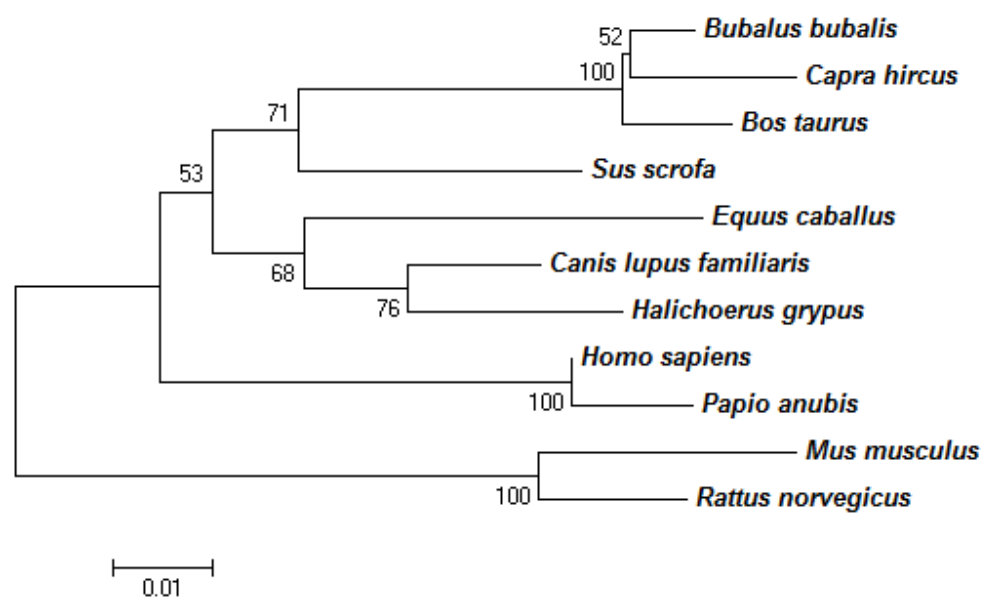

Figure 7. Phylogenetic tree constructed based on eleven amino acid sequences of PTHrP protein from Bubalus bubalis (JX962778), Bos taurus (NP_777178), Canis lupus familiaris (NP_001003303), Capra hircus (ADK36630), Equus caballus (NP_001157453), Halichoerus grypus (CAH39861), Homo sapiens (NP_945316), Mus musculus (NP_032996), Papio anubis (XP_003906208), Rattus norvegicus (NP_036768), and Sus scrofa (NP_999081). 


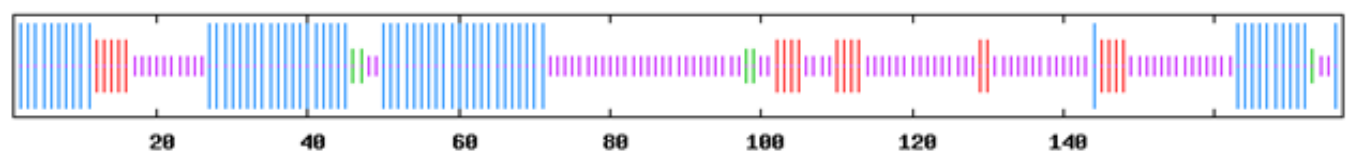

Figure 8. Secondary structure of the water buffalo PTHrP protein predicted by SOPMA. Alpha helices, extended strands, beta turns, random coils, are denoted with the longest, second longest, third longest, and shortest vertical lines, respectively.

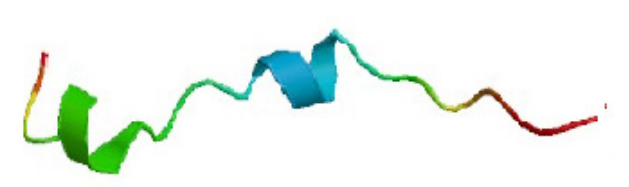

(a)

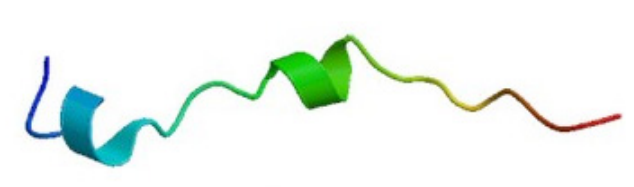

(b) Figure 9. a. 3-D structure of water buffalo PTHrP; $b .3-$ - 3 structure of the human PTHrP
structure of water buffalo PTHrP was similar to that of humans with $99.9 \%$ identity.

\section{Tissue expression profile analysis}

The PTHrP gene was only expressed in 5 tissues, including the adipose tissue, placenta, uterine wall, hypophysis, and mammary gland tissues. The protein was highly expressed in the adipose tissue and uterine wall, moderately expressed in the placenta, lowly expressed in the hypophysis and mammary gland, and was nearly non-expressed in the heart, liver, spleen, lung, kidney, pancreas, duodenum, cerebrum, ovary, skin, and longissimus dorsi. Expression levels of the PTHrP gene in various buffalo tissues are presented in Figure 10.

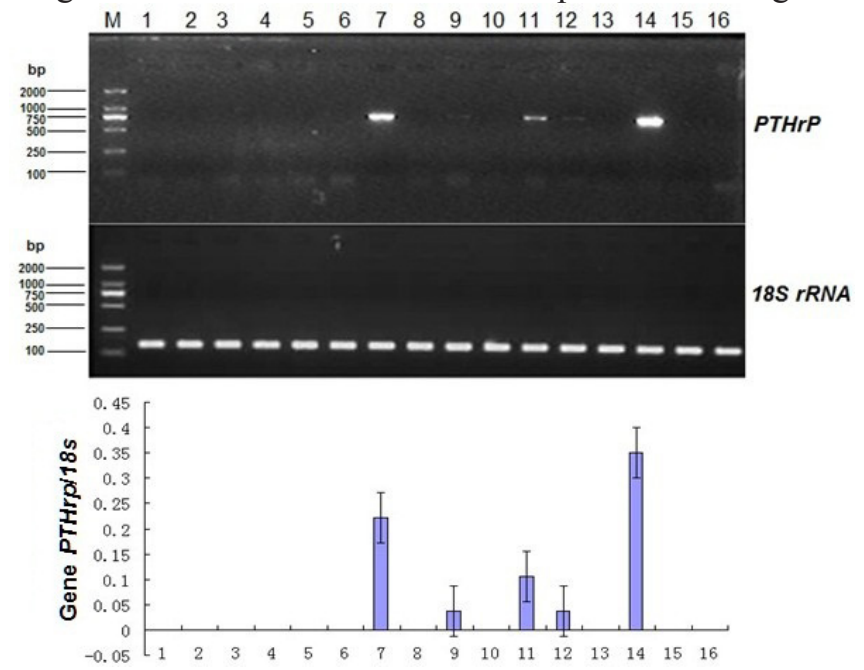

Figure 10. Tissue expression profile of water buffalo $P T H r P$ gene. $18 S r R N A$ was used as the internal control. Lane $M=$ DL 2000 DNA marker; lane 1 = heart; lane $2=$ liver; lane $3=$ spleen; lane $4=$ lung; lane 5 = kidney; lane 6 = pancreas; lane $7=$ adipose tissue; lane $8=$ duodenum; lane $9=$ hypophysis; lane $10=$ cerebrum; lane $11=$ placenta; lane $12=$ mammary gland; lane 13 = ovary; lane 14 = uterus wall; lane 15 = skin; lane $16=$ longissimus dorsi. 


\section{DISCUSSION}

Previous studies in cattle and goat have suggested that PTHrP was synthesized in alveolar epithelial cells of lactating mammary glands and subsequently entered milk and the maternal circulation, where it participated in regulating local calcium homeostasis and lactogenesis of the mammary gland (Ratcliffe et al., 1992; Thiede, 1994; Onda et al., 2006a). Studies in humans and mice demonstrated that the PTHrP gene can increase cell proliferation in the vascular smooth muscle and participate in the development of mammary glands (Massfelder et al., 1997; Wysolmerski, 2008). In the current study, the PTHrP gene was first identified in water buffalo. The cloning and sequencing showed that the full-length CDS of the water buffalo PTHrP gene contains 534 bp and encodes a protein composed of 177 amino acid residues, which is the same as that of cattle and goat. In addition, there were no polymorphisms found in the PTHrP CDS, indicating that the PTHrP gene is conserved in water buffalo. Analysis of molecular characteristics revealed that water buffalo PTHrP might play crucial roles in the cell nucleus with high reliability. This protein has no transmembrane region and contains a signal peptide, indicating that PTHrP is a secretory protein. Sequence alignment indicated that PTHrP is highly conserved among mammalian species. Phylogenetic analysis showed that water buffalo PTHrP has a close genetic relationship with cattle and goat. The results of structural analysis showed that the 3-D structure of water buffalo PTHrP is similar to that of humans, with $99.9 \%$ identity, and a domain of parathyroid superfamily was found in water buffalo PTHrP that shares high identity with that of other mammal species. These results imply that water buffalo PTHrP may have a similar genetic function with other mammals, particularly with cattle or goat, in the regulation of cell proliferation, local calcium homeostasis, and lactogenesis of the mammary gland.

Some previous studies showed that the PTHrP gene is widely expressed in various normal tissues, such as the uterus (myometrium and endometrium), brain, heart, mammary gland, kidney, lung, liver, pancreas, placenta, bone, muscle, pituitary, spleen, and ovary, among others (Clemens et al., 2001; Thota et al., 2005). In this study, we found that the water buffalo $P T H r P$ gene was expressed with a different pattern from the above results. Among the 16 tested tissues of water buffalo, the protein was only expressed in the adipose tissue, uterine wall, placenta, mammary gland, and hypophysis, with high expression in the adipose tissue and uterine wall, moderate expression in the placenta, and low expression in the mammary gland and hypophysis. The different expression of the water buffalo PTHrP gene compared to previous results may be related to the species, physiological conditions, and nutritional level. However, the expression of water buffalo PTHrP gene in the present study was consistent with the expected role of this gene. A previous study in lactating rat suggested that $P T H r P$ was expressed in alveolar epithelial cells and stromal fibroblasts of the mammary gland, supporting a paracine or autocrine role of PTHrP in these 2 cell types (Wojcik et al., 1999). In milk goat, $P \operatorname{THr} P$ was found to be highly expressed in the mammary gland (Yang et al., 2010). Past studies in cow showed that $P T H r P$ was expressed in the mammary gland during late pregnancy and increased subsequently with lactation, suggesting that PTHrP is involved in regulating local Ca homeostasis (Wojcik et al., 1998; Onda et al., 2006b). The physiological function of a protein may indicate its tissue distribution. We found that water buffalo $\mathrm{PTHr} P$ was expressed at low levels in the mammary glands during the perinatal period, which is similar to the result in cows. Thus, the PTHrP gene may have similar roles in the paracine 
or autocrine regulation of local $\mathrm{Ca}$ homeostasis. A previous study reported that $\mathrm{PTHr} P$ was expressed in the placenta and was present at high levels in the fetal circulation, supporting that PTHrP stimulates placental calcium transfer (Simmonds and Kovacs, 2010). The PTHrP gene was moderately expressed in the water buffalo placenta in this study, indicating that PTHrP in water buffalo may play a role in placental calcium transfer.

In the dairy and meat industries, water buffalo has potential economic value. Water buffalo contribute more than $5 \%$ of total annual milk production worldwide, ranking second after bovine milk (Han et al., 2012). PTHrP protein is a paracine or autocrine factor that functions in cell proliferation, calcium homeostasis, and the regulation of lactogenesis. Therefore, $P T H r P$ is a functional candidate gene for milk traits in farm animals. In the present study, we successfully isolated the water buffalo $P T H r P$ gene. Bioinformatic analysis revealed that water buffalo PTHrP might have similar biological functions with other species. In addition, we found that water buffalo $P T H r P$ gene is expressed in the adipose tissue, placenta, uterine wall, hypophysis, and mammary gland, indicating its functional roles in these tissues. The results presented here establish a primary foundation for further investigations into the role and functional mechanism of the water buffalo $P T H r P$ gene.

\section{ACKNOWLEDGMENTS}

Research supported by the Natural Science Foundation Key Project of Yunnan Province, China (\#2014FA032 and \#2007C0003Z), the National Natural Science Foundation of China (\#31460582 and \#30660024), the Applied and Basic Research Foundation of Yunnan Province, China (\#2006C0034M), and the Foundation of Yunnan Department of Finance, China (Study on the germplasm characteristics of Binglangjiang water buffalo).

\section{REFERENCES}

Amizuka N, Oda K, Shimomura J and Maeda T (2002). Biological action of parathyroid hormone (PTH)-related peptide (PTHrP) mediated either by the PTH/PTHrP receptor or the nucleolar translocation in chondrocytes. Anat. Sci. Int. 77: 225-236.

Boras-Granic K and Wysolmerski JJ (2012). PTHrP and breast cancer: more than hypercalcemia and bone metastases. Breast Cancer Res. 14: 307.

Bouvet M, Nardin SR, Burton DW, Lee NC, et al. (2002). Parathyroid hormone-related protein as a novel tumor marker in pancreatic adenocarcinoma. Pancreas 24: 284-290.

Clemens TL, Cormier S, Eichinger A, Endlich K, et al. (2001). Parathyroid hormone-related protein and its receptors: nuclear functions and roles in the renal and cardiovascular systems, the placental trophoblasts and the pancreatic islets. Br. J. Pharmacol. 134: 1113-1136.

Deftos LJ (2002). Hypercalcemia in malignant and inflammatory diseases. Endocrinol. Metab. Clin. North Am. 31: 141158.

Escande B, Lindner V, Massfelder T, Helwig JJ, et al. (2001). Developmental aspects of parathyroid hormone-related protein biology. Semin. Perinatol. 25: 76-84.

Han X, Lee FL, Zhang L and Guo MR (2012). Chemical composition of water buffalo milk and its low-fat symbiotic yogurt development. Funct. Foods Health Disease 2: 86-106.

Hastings RH (2004). Parathyroid hormone-related protein and lung biology. Respir. Physiol. Neurobiol. 142: 95-113.

Hoey RP, Sanderson C, Iddon J, Brady G, et al. (2003). The parathyroid hormone-related protein receptor is expressed in breast cancer bone metastases and promotes autocrine proliferation in breast carcinoma cells. Br. J. Cancer 88: 567-573.

Karaplis AC, Luz A, Glowacki J, Bronson RT, et al. (1994). Lethal skeletal dysplasia from targeted disruption of the parathyroid hormone-related peptide gene. Genes Dev. 8: 277-289.

Lam MH, Thomas RJ, Martin TJ, Gillespie MT, et al. (2000). Nuclear and nucleolar localization of parathyroid hormone-

Genetics and Molecular Research 14 (1): 2290-2301 (2015)

CFUNPEC-RP www.funpecrp.com.br 
related protein. Immunol. Cell Biol. 78: 395-402.

Lanske B, Karaplis AC, Lee K, Luz A, et al. (1996). PTH/PTHrP receptor in early development and Indian hedgehogregulated bone growth. Science 273: 663-666.

Li J, Karaplis AC, Huang DC, Siegel PM, et al. (2011). PTHrP drives breast tumor initiation, progression, and metastasis in mice and is a potential therapy target. J. Clin. Invest. 121: 4655-4669.

Martin TJ, Allan EH, Caple IW, Care AD, et al. (1989). Parathyroid hormone-related protein: isolation, molecular cloning, and mechanism of action. Recent Prog. Horm. Res. 45: 467-502; discussion 502-506.

Massfelder T, Dann P, Wu TL, Vasavada R, et al. (1997). Opposing mitogenic and anti-mitogenic actions of parathyroid hormone-related protein in vascular smooth muscle cells: a critical role for nuclear targeting. Proc. Natl. Acad. Sci. U. S. A. 94: 13630-13635.

Moseley JM, Kubota M, Diefenbach-Jagger H, Wettenhall RE, et al. (1987). Parathyroid hormone-related protein purified from a human lung cancer cell line. Proc. Natl. Acad. Sci. U. S. A. 84: 5048-5052.

Onda K, Sato A, Yamaguchi M, Matsuki N, et al. (2006a). Parathyroid hormone-related protein (PTHrP) and Ca levels in the milk of lactating cows. J. Vet. Med. Sci. 68: 709-713.

Onda K, Matsuki N, Ono K and Wada Y (2006b). Expression of parathyroid hormone-related protein (PTHrP) mRNA in mammary gland of periparturient cows. J. Vet. Med. Sci. 68: 9-13.

Ratcliffe WA, Thompson GE, Care AD and Peaker M (1992). Production of parathyroid hormone-related protein by the mammary gland of the goat. J. Endocrinol. 133: 87-93.

Schlüter KD (1999). PTH and PTHrP: similar structures but different functions. News Physiol. Sci. 14: 243-249.

Simmonds CS and Kovacs CS (2010). Role of parathyroid hormone (PTH) and PTH-related protein (PTHrP) in regulating mineral homeostasis during fetal development. Crit. Rev. Eukaryot. Gene Expr. 20: 235-273.

Stewart AF (2002). Hyperparathyroidism, humoral hypercalcemia of malignancy, and the anabolic actions of parathyroid hormone and parathyroid hormone-related protein on the skeleton. J. Bone Miner. Res. 17: 758-762.

Thiede MA (1994). Parathyroid hormone-related protein: a regulated calcium-mobilizing product of the mammary gland. J. Dairy Sci. 77: 1952-1963.

Thota CS, Reed LC and Yallampalli C (2005). Effects of parathyroid hormone like hormone (PTHLH) antagonist, PTHLH7-34, on fetoplacental development and growth during midgestation in rats. Biol. Reprod. 73: 1191-1198.

VanHouten JN, Dann P, Stewart AF, Watson CJ, et al. (2003). Mammary-specific deletion of parathyroid hormone-related protein preserves bone mass during lactation. J. Clin. Invest. 112: 1429-1436.

Wojcik SF, Schanbacher FL, McCauley LK, Zhou H, et al. (1998). Cloning of bovine parathyroid hormone-related protein (PTHrP) cDNA and expression of PTHrP mRNA in the bovine mammary gland. J. Mol. Endocrinol. 20: 271-280.

Wojcik SF, Capen CC and Rosol TJ (1999). Expression of PTHrP and the PTH/PTHrP receptor in purified alveolar epithelial cells, myoepithelial cells, and stromal fibroblasts derived from the lactating rat mammary gland. Exp. Cell Res. 248: 415-422.

Wysolmerski J (2008). Parathyroid Hormone-Related Protein. In: Primer on the Metabolic Bone Diseases and Disorders of Mineral Metabolism. 7th ed. (Rosen C, ed.). American Society for Bone and Mineral Research, Washington, DC, 127-133.

Wysolmerski JJ, McCaughern-Carucci JF, Daifotis AG, Broadus AE, et al. (1995). Overexpression of parathyroid hormone-related protein or parathyroid hormone in transgenic mice impairs branching morphogenesis during mammary gland development. Development 121: 3539-3547.

Yang ZY, Zheng HL and Ruifang X (2010). Cloning of Capra hircus PTHrP and its prokaryotic expression in Escherichia coli. J. Northwest A \& F Univ. 10: 010. 